\title{
ATLAS OBSCURA
}

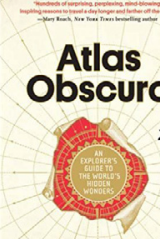

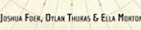

By Joshua Foer, Dylan Thuras, and Ella Morton

Workman Publishing, 2016

470 pages, $\$ 35.00$, hardcover.

ISBN: 978-0-7611-6908-6

\section{Review by: Bob Hickey, Central Washington University}

Unlike the subjects of other reviews I have written, Atlas Obscura is neither a textbook nor a normal book. It's more of a very selective encyclopedia.

As such, it isn't something one normally would sit down and read-nor is it something I would assign to a student.

That said, it was great fun to flip through, and it's something I'll reference before future trips!

So, what is it? Atlas Obscura is a compendium of 600 odd, weird, different, obscure, spectacular, and gross places you can visit-with a few random lists tossed in to break things up. Is it subjective? You betcha. Is it comprehensive? By no means, but it is something to supplement your Lonely Planet guide with little or no overlap. For those who travel, it's fun both to look for places already visited and to find new hangouts.

The book is organized first by continent, then subdivided geographically; it also has a special topical index in the back.

Because there is no good way to describe the incredible variety of places it presents, I'll organize and highlight a few of my favorites. First is the Globe Museum in Vienna. I've been there-it's pretty much porn for map nerds. Original Mercator globes are the top attractions.

If we consider "cultural" sites, the "can't miss" selection includes: the UTA Flight 772 Memorial in middle-of-nowhere Niger; the Bordello Museum in Wallace, Idaho; Yamamoto's Bomber in Papua New Guinea; the African Renaissance Monument in Dakar, Senegal (twice as large as the Statue of Liberty!); and, of course, Carhenge in Nebraska.

Moving on to Ma Nature, check out: the falcon hospital in Abu Dhabi; the crooked forest in Poland; the bioluminescent firefly squid of Toyama Bay; Costa Rica's sloth sanctuary; and Archie, a giant squid at the Natural History Museum in London (or the colossal squid at the Te Papa Museum, New Zealand).

If body parts are your thing, Galileo's middle finger can be viewed in Florence. Then, there's the Museum of Death in Hollywood. But the epic choice would be the Musée Fragonard (Paris) - where a fair-sized troop of flayed bodies can be viewed. While there, be sure not to miss the horseman of the apocalypse: a deceased rider flogging a dead horse.

For the straight up odd stuff, I'll begin where Atlas Obscura begins, in the United Kingdom with the Silver Swan, an automaton built in the 1770s. For pure excitement, you will want to see the pitch drop experiment at the University of Queensland; if you're lucky, you'll see a drop fall (it happens every 12-13 years). The longest operating light bulb (since 1901) can be viewed in Livermore, California, and the world's largest tesla coil resides in Makarau, New Zealand.

No list, though, would be complete without at least some of the places that most of us would recognize. These include places like Socotra Island (Yemen), Yosemite (California), Hobbiton (New Zealand), Batu Caves (Indonesia-where monkeys will try to steal your postcards. Trust me, watch out for them), the City of the Dead (Cairo, Egypt), or the Nazca Lines (Peru).

There are also the places you should not visit. Topping this category is North Sentinel Island (India) - a place where non-locals go to be attacked and/or killed. Seriously, just stay away. Ditto, Snake Island (Brazil) - even I, a lover of snakes, will take a pass on this one. For "tough to get to," check out the bust of Lenin at the South Pole of Inaccessibility (the spot farthest from the coast). You can 
round your list off with the infamous Sourtoe Cocktail in Dawson City, Canada. Yup, a cocktail with a dead (and well preserved in high-proof alcohol) human toe floating in your drink.

I've saved for last a couple of places that simply make you ask "why?": the Gopher Hole Museum in Canada and the Weeki Wachee Mermaids in Florida.

For those who have read this far, my advice is to buy a copy of Atlas Obscura. It's fun, interesting, and a potential travel guide to many places around the world. Sadly, though, it failed me in my first attempt at using it as a travel guide: there isn't anything listed in the Shetland Islands (where a friend of mine is going in January). My disappointment, however, was premature: a visit to their website (atlasobscura.com, where over 12,500 entries of even more odd stuff can be found) turned up four attractions in the Shetlands. I'm just about to email my buddy and bookmark the site!

\section{MAKING SPATIAL DECISIONS USING ARCGIS PRO: A WORKBOOK}

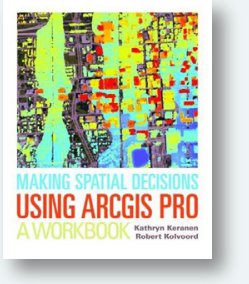

By Kathryn Keranen and Robert Kolvoord

Esri Press, 2017

376 pages, $\$ 69.99$, softcover.

ISBN: 978-1-58948-484-9

Review by: Amanda Tickner, Michigan State University Library

\section{Making Spatial Decisions Using ArcGIS Pro: A Workbook} is the fourth in a series of GIS workbooks by Kathryn Keranen and Robert Kolvoord. Both authors have backgrounds in $\mathrm{K}-12$ and higher education, and their experience is reflected in a text that is straightforward and approachable for audiences from high school on up. This new volume is consistent with others in the series, with a key difference being length: it is substantially longer, with more, and somewhat more extensive, exercises. While several of the exercises are essentially repetitions of those found in earlier series entries - they use the same structure and data to create similar outputs- the exercises have been updated to work in and with the ArcGIS Pro software.

ArcGIS Pro is relatively new, released in 2015, and, unlike earlier iterations of ArcMap, is a genuinely new piece of software. The tools are similar between ArcMap and ArcGIS Pro, but the workflow is very different between the two. In 2020, Esri plans to sunset the ArcMap desktop application in favor of ArcGIS Pro, and this workbook is a useful addition to the as-yet relatively scarce resources available to address this impending changeover.

The authors clearly assume that the reader will have some basic experience with both ArcGIS Pro and with GIS in general, assumptions that might seem to contradict the book's implied suitability as an introductory GIS text. However, in this reviewer's estimation, most of the exercises can be mastered with only the most basic understanding of GIS. Familiarity with mapping using ArcGIS Online, and access to an ArcGIS Online organizational account, are also assumed. Many modules, for example, involve accessing online data and while the process steps are given, familiarity and experience are helpful.

The workbook exercises are divided into nine modules, each with two projects. In general, the first project of each module has step-by-step instructions, while the second is less detailed but covers similar materials and processes. This is a nice pattern: the first project is very cookbook-like, while in the second, the user applies the tools without so much hand-holding, but still with guidance and a provided dataset.

The topics and themes vary in kind from module to module. An example of a more planning/government-type scenario (though not labeled as such) is "Module 1: Hazardous Emergency Decisions," which presents a scenario around a "homeland security" situation involving a chemical spill on a highway. It requires creation of a map of detour routes and relevant facilities within a certain drive time. There are also more environmentally focused scenarios, such as "Module 9: Forest Vegetation Height," which uses lidar data to observe and manage a forest area.

This variety of topics could be looked at positively (there is likely something relevant for everyone in one module or another) or negatively (many topics may seem irrelevant for users focused on a particular discipline). The lack 